\title{
The association between health literacy and indicators of cognitive impairment in a diverse sample of primary care patients
}

\author{
Kathleen J. Yost ${ }^{a},{ }^{*}$, Darren A. DeWalt ${ }^{b}$, Lee A. Lindquist ${ }^{c}$, and Elizabeth A. Hahn ${ }^{d}$ \\ aDepartment of Health Sciences Research, Mayo Clinic, USA \\ ${ }^{b}$ General Medicine and Clinical Epidemiology, University of North Carolina at Chapel Hill, USA \\ 'Department of Medicine, Northwestern University Feinberg School of Medicine, USA \\ dDepartment of Medical Social Sciences, Northwestern University Feinberg School of Medicine, \\ USA
}

\section{Abstract}

Objectives-To confirm the association of health literacy scores as measured by Health Literacy Assessment Using Talking Touchscreen Technology (Health LiTT) with cognitive ability and education. To determine whether this association differs by cognitive task.

\begin{abstract}
Methods-Cognitive impairment was measured using the Mini-Cog, which combines a delayed word recall task (WRT) and a clock drawing task (CDT) to yield an overall classification of normal versus cognitively impaired. Participants were recruited from primary care clinics that provide care to underserved patients.
\end{abstract}

Results-Participants $(\mathrm{n}=574)$ were predominantly non-Hispanic black $(67 \%)$ with a mean age of 46 years, $50 \%$ did not have health insurance, $56 \%$ had a high school education or less and $21 \%$ screened positive for cognitive impairment. Overall cognitive ability and education were significantly associated with health literacy after adjusting for other variables, including race/ ethnicity and physical health. We observed a stronger association between the CDT and health literacy than between the WRT and health literacy.

Conclusion-By confirming hypothesized associations, this study provides additional support of the validity of Health LiTT.

Practice implications-Health LiTT is a reliable and valid tool that researchers and clinicians can use to identify individuals who might have difficulty understanding health information.

\footnotetext{
(C) 2013 Elsevier Ireland Ltd. All rights reserved.

*Corresponding author at: Department of Health Sciences Research, Mayo Clinic, 200 First Street Southwest, Rochester, MN 55905, USA. Tel.: +1 507538 3894; fax: +1 507284 1516, yost.kathleen@ mayo.edu.

Publisher's Disclaimer: This is a PDF file of an unedited manuscript that has been accepted for publication. As a service to our customers we are providing this early version of the manuscript. The manuscript will undergo copyediting, typesetting, and review of the resulting proof before it is published in its final citable form. Please note that during the production process errors may be discovered which could affect the content, and all legal disclaimers that apply to the journal pertain.

Portions of this manuscript were presented at the Health Literacy 2nd Annual Research Conference, Bethesda MD, October 18-19, 2010.

Conflict of interest

No conflicts of interest were reported by any of the authors.

The authors confirm that all patient/personal identifiers have been removed or disguised so the patients described are not identifiable and cannot be identified through the details of the story.
} 


\section{Keywords}

Health literacy; Cognitive impairment; Cognitive function; Vulnerable populations; Validity

\section{Introduction}

Health Literacy Assessment Using Talking Touchscreen Technology (Health LiTT) is a new computer-based tool that can be used in clinical practice and research to assess patients' health literacy $[1,2]$. For the purpose of this measurement tool, we define health literacy as the capacity to read and comprehend health-related print material, identify and interpret information presented in graphical format (charts, graphs and tables), and perform arithmetic operations in order to make appropriate health and care decisions [3]. Health LiTT was created to measure a breadth of literacy levels and can be administered as a short form test or using computer adaptive testing (CAT). CAT uses computer algorithms to select the best test items based on responses to previous items. This approach minimizes the assessment length, while maximizing the precision of the measurement of health literacy. As a new tool, it is important to know how Health LiTT is related to other commonly used measures in the health care setting: 1) cognitive ability, and 2) years of education.

Health LiTT has been shown to be acceptable to a wide variety of patients, including those who are computer naïve and older [2], and initial evidence supports the validity of this new tool $[1,4]$. Validation of a new measurement tool requires building a weight of evidence demonstrating that the instrument is measuring the construct of interest and that the scores behave as hypothesized [5]. Two variables consistently shown to be independently associated with better health literacy in numerous previous studies are normal cognitive ability and higher educational attainment [6-13]. The relationship between health literacy, cognitive ability, and education is complex and the causal direction of the associations is difficult to tease apart [8]. However, demonstrating independent associations of cognitive ability and education with health literacy as measured by Health LiTT would further support the validity of this new measure.

The overall objective of this study was to determine whether the established associations between health literacy, education, and cognitive ability are confirmed when health literacy is measured by the new Health LiTT. The strength of association between health literacy and cognitive ability may vary by how these constructs are measured [13]. Thus, a secondary objective was to assess whether the association between health literacy and cognitive ability differed by type of cognitive task.

\section{Methods}

\subsection{Participants}

Data for this unplanned secondary analysis were from a sample of primary care patients who participated in a study to develop and calibrate Health LiTT [1,2]. Participants in the parent study were recruited from two urban and two suburban primary care clinics that provide care to underserved patients, many of whom do not have health insurance. Two recruitment methods were used at both clinics: flyers posted near the reception desk and direct invitation by a research assistant in the waiting area. Eligibility criteria for the parent study included age 21 years or older, English-speaking, and sufficient hearing, vision, cognitive function, and manual dexterity to interact with the touchscreen laptop as judged by the research assistant during the enrollment process [1, 2]. Informed consent was obtained from all participants in accordance with institutional review board requirements. Participants received \$20 for completing the assessment. 


\subsection{Measures}

Health LiTT assesses three types of health literacy skills: prose, document, and quantitative. Prose literacy focuses on the understanding and use of information from texts; document literacy requires the ability to locate and use information from forms, tables, graphs, etc.; and quantitative literacy requires the ability to apply arithmetic operations using numbers embedded in printed materials. With Health LiTT, one question at a time is displayed on the touchscreen. All document and quantitative items are accompanied by an audio recording of the question to mitigate the influence of reading comprehension on measuring those skills (see example document item below). All participants answered Health LiTT items on a touchscreen laptop computer. To reduce respondent burden, we separated the item bank into six overlapping subsets of 30 Health LiTT items. The six subsets were administered sequentially (i.e., in order of patient enrollment) to obtain equal numbers of completions for each subset. See Yost et al. and Hahn et al. for more detail on the parent study [1, 2].

The respondent may touch a sound icon on the screen to hear the audio as many times as needed. An answer is selected by touching one of the response buttons. Once selected, the button changes in color providing visual confirmation of the chosen response. The respondent then advances to a new screen for the next question. Health LiTT is based on a calibrated item bank of 82 items, and health literacy is scored on a T-score scale that has a mean of 50 and standard deviation of 10 in the calibration sample [1]. Higher scores indicate higher levels of health literacy.

The primary objective of the parent study was to assess the psychometric properties of the Health LiTT item bank [14]. Cognitive ability was included as a potential covariate for secondary analyses. As it was not a critical variable for the parent study, we investigated very brief tools for measuring cognitive impairment. We selected the Mini-Cog screening tool consisting of a delayed three-item word recall task (WRT) measuring short-term memory and a clock drawing task (CDT) measuring visuospatial skills. Sensitivity and specificity for the Mini-Cog to identify dementia are $75 \%$ and $89 \%$, respectively in the general population [15] and 99\% and 93\%, respectively among elderly [16]. Since the MiniCog is a screening tool, participants in our study should not be deemed "cognitively impaired" without additional testing [17]. Rather, they should be considered as having "screened positive" for cognitive impairment.

The WRT score can range from $0=$ no words recalled correctly to $3=$ all words (apple, table, penny) recalled correctly; therefore, a low WRT score indicates cognitive impairment. The clock drawings were scored by two independent, experienced psychometrists using the four-point Consortium to Establish a Registry for Alzheimer's Disease (CERAD) scoring where 0 is normal and 1-3 represent increasing levels of cognitive impairment [18, 19]; thus, a high CDT score indicates cognitive impairment. Clock drawings for 30 participants were scored by both psychometrists and discussed for purposes of calibrating their scoring; these drawings were excluded from the inter-rater reliability analyses. If inter-rater reliability for the remaining CDT drawings was high, defined as a weighted kappa $>0.74$ [20], then the CDT score of the more senior psychometrist was used in determining the overall Mini-Cog score for a patient. If the inter-rater reliability was not high, the average of the CDT scores from the two psychometrists was used. The WRT and CDT scores were combined using the algorithm described by Borson et al. [16] to yield an overall Mini-Cog classification of $0=$ normal versus $1=$ cognitively impaired. Specifically, if a person recalls all three words correctly, s/he is classified as having normal cognitive function (i.e., negative screen). If all three words are missed, the person is classified as cognitively impaired (i.e., positive screen). The clock drawing is only considered in the Mini-Cog scoring algorithm if a person recalls one or two words, in which case a normal clock drawing (score $=0$ ) leads to a classification of normal cognitive function (i.e., negative screen) and an impaired clock 
drawing (score $=1,2$ or 3 ) leads to a classification of cognitively impaired (i.e., positive screen).

Standard sociodemographic and clinical variables were obtained via intervieweradministered questionnaires. Education was measured as the highest grade level completed and then categorized for purposes of analysis. Health status was measured with the global mental health and global physical health scales from the Patient-Reported Outcomes Measurement Information System (PROMIS) [21]. These two global scales are scored on a T-score scale, with a mean of 50 and a standard deviation of 10 in the general population. Higher global scores indicate better health.

\subsection{Statistical analyses}

We described the cognitive ability of the sample and we assessed whether cognitive ability was associated with recruitment site, age, gender, race/ethnicity, education, household income, health status and health literacy using chi-square tests and t-tests, as appropriate. We evaluated the association between education, cognitive ability and health literacy adjusted for other sociodemographic and health-related variables using multivariable linear regression. We first assessed each variable in a simple linear regression to obtain unadjusted estimates of their association with health literacy, the dependent variable. We then conducted a stepwise multivariable regression analysis of health literacy scores to determine the unique amount of variance in health literacy that is explained by education and cognitive ability. Recruitment site, age, gender, race/ethnicity, income and health status were entered in Step 1; education was entered in Step 2; and cognitive impairment was entered in Step 3. In a sensitivity analysis, we replaced the overall Mini-Cog classification (normal versus screen positive for cognitive impairment) with its separate components (i.e., the WRT and CDT scores) to determine whether the model interpretations would remain unchanged.

\section{Results}

\subsection{Participants}

All patients who were approached appeared to have sufficient cognitive function to provide informed consent and sufficient ability to interact with the touchscreen computer [2]. No patients were excluded based on an inability to provide consent or interact with the computer. Enrollment rates were very high at both the suburban (90.3\%) and urban (90.0\%) sites. For those who chose not to participate, the primary reason given was not enough time to complete the assessment. Overall Mini-cog classification and complete Health LiTT data were available for 574 of the 610 participants in the parent Health LiTT calibration study. Sample characteristics presented in Table 1 demonstrate that the participants comprise a vulnerable population based on the high proportion that are minority $(84 \%)$, have household income less than $\$ 10,000(42 \%)$, and are uninsured (50\%).

\subsection{Cognitive impairment}

Agreement between the two psychometrists who scored the CDT was very good (weighted kappa 0.755); therefore, we used the CDT scores from the senior psychometrist in the MiniCog algorithm. Most participants $(n=387,67.4 \%)$ were able to correctly recall all three words in the WRT; in contrast, clock drawings were normal for only 233 (40.6\%) participants. These results suggest that the CDT was a more difficult task for the participants than the WRT. The clock drawing was considered in the Mini-Cog scoring for the 180 participants who correctly recalled only one or two words as shown in Figure 2. Of these, 111 had abnormal clock drawings and were classified as cognitively impaired and 69 had normal drawings and were classified as having normal cognitive function. Overall, 118 (20.6\%) patients were classified as having screened positive for cognitive impairment. 
Participants who screened positive for cognitive impairment were significantly $(\mathrm{p}<0.05)$ more likely to be older, recruited from suburban clinics, have worse mental health, and lower health literacy (Tables $2 \mathrm{a}$ and $2 \mathrm{~b}$ ). Physical health, race/ethnicity, and household income approached a statistically significant association $(\mathrm{p}<0.10)$ with cognitive impairment.

\subsection{Health literacy}

The variables that explained the most variance in Health LiTT scores in the simple linear regression analyses (Table 3$)$ were race/ethnicity $\left(r^{2}=13.1 \%\right)$, education $\left(r^{2}=11.9 \%\right)$ and $\operatorname{CDT}\left(r^{2}=5.7 \%\right)$. The results for the simple (Table 3 ) and multivariable (Table 4) regression analyses were fairly consistent; that is, variables that were significantly associated with health literacy in the simple regression remained significant when adjusted for other variables in the multivariable regression with the exception of household income. The model adjusted $\mathrm{R}^{2}$ increased from $14.8 \%$ in Step 1 to $24.0 \%$ in Step 2 with the addition of education. Overall cognitive impairment, added in Step 3, increased the adjusted $\mathrm{R}^{2}$ only slightly to $25.6 \%$ and was significantly associated with health literacy independent of education. Health LiTT T-scores for patients who screened positive for cognitive impairment were 3.3 points lower $(\mathrm{p}<0.001$ ) than scores for people with normal cognitive function (Table 4, Step 3). Education was also significantly associated with health literacy independent of cognitive impairment; patients with some college and those with a college degree or higher scored an average of 4.3 and 9.8 points higher on Health LiTT, respectively, than patients with less than a high school education (Table 4, Step 3). Urban recruitment site and good physical health were significantly associated with higher health literacy scores. Minority participants had health literacy scores that were significantly lower than those for white participants.

\subsection{Sensitivity analysis}

The CDT accounted for more variance in health literacy $\left(\mathrm{r}^{2}=5.7 \%\right)$ in the simple regression analysis than either the WRT $\left(r^{2}=2.3 \%\right)$ or overall cognitive impairment $\left(\mathrm{r}^{2}=3.2 \%\right.$ ) (Table 3 ). While the CDT and WRT were both highly statistically significant in the simple linear regression, only the CDT remained significant in the multivariable model. Compared to the model in Step 2, which had an adjusted $\mathrm{R}^{2}$ of $24.0 \%$, adding overall cognitive impairment in Step 3 only improved the adjusted $\mathrm{R}^{2}$ by $1.6 \%$. In contrast, adding the separate WRT and CDT components of the Mini-Cog screener in Step $3^{b}$ increased the adjusted $\mathrm{R}^{2}$ by $3.7 \%$ compared to the model in Step 2 (Table 4). Thus, slightly more variance in health literacy is explained when cognitive impairment is measured by the two component scores rather than the overall dichotomous classification. We also computed the standardized regression coefficients and squared semi-partial correlations for CDT and WRT in the Step $3^{\mathrm{b}}$ model. The standardized regression coefficients (and squared semi-partial correlation) were -0.19 (0.035) for CDT and 0.07 (0.005) for WRT further indicating that the CDT was more strongly associated with health literacy than WRT.

\section{Discussion and conclusion}

\subsection{Cognitive impairment}

The proportion of participants who screened positive for cognitive impairment by the MiniCog in our study was $20.6 \%$, which is quite high considering that the prevalence of dementia in the general population as determined by the Mini-Cog is only 6.4\% [15]. Performance on tests of cognitive function may vary with social conditions over the lifecourse or by race/ ethnicity, educational attainment, education quality, and literacy skills [22-24]. It is possible that in a vulnerable population like the one in this study (i.e., minority, poor, low educational attainment), the cognitive abilities assessed by the Mini-Cog were never 
adequately developed, were not maintained once developed, or that the screener is biased by culture or educational background. The roughly $21 \%$ of our relatively young sample who screened positive for cognitive impairment may indeed have limited abilities with short-term memory and/or visuospatial skills, but the etiology may be environmental rather than neurological. For example, several participants wrote the time in digital format as "11:10" in the circle intended for the clock drawing, suggesting they either did not understand the task or were not practiced in how to complete the task of drawing a clock face. Increased exposure to digital clocks and/or decreased exposure to analog clocks may increase the difficulty of the CDT task; however, it is unlikely to be solely responsible for the high rate of subjects with positive Mini-Cog screens in our study. Rather, we suspect other educational, race/ethnic or cultural biases are more likely to be responsible. Education and culture can bias performance on the CDT [25-27] and education can bias the WRT [28]. The impact of respondent characteristics on cognitive test performance can be profound. For example, in one study, $6 \%$ of non-impaired white subjects screened positive on the Minimental State Examination compared to $42 \%$ of non-impaired black subjects [29]. While the Mini-Cog has been shown to perform well in multiethnic samples and is considered to be less susceptible to bias due to low education and low literacy than other screening tools [16, 30], these studies were based on samples that were older and had lower proportions of African-Americans than our sample (i.e., $22 \%$ [30] and 24\% [16] vs. $67 \%$ in our sample). It is not clear whether the Mini-Cog performs equally well in a younger, predominantly African-American population.

The associations between cognitive impairment and other study variables were fairly consistent with published literature on the correlates of dementia [31] with a few exceptions; we anticipated that higher education would be inversely associated with cognitive impairment and that more women than men would be cognitively impaired. As most of the research on the correlates of cognitive function has been done in elderly populations, the lack of statistically significant associations with these variables may be due to the relatively younger age of our study sample (mean 46.1 years, SD 11.8 years). When restricted to participants 60 years of age and older $(n=57)$, the associations between education, gender, and cognitive impairment trended more in the expected direction, although still not statistically significant (data not shown). In addition, the quality of education for minorities may be lower than that for whites [32], which may also explain the lack of an association between education and cognitive impairment in our predominantly minority sample.

\subsection{Health literacy}

We confirmed the independent associations between health literacy and both education and cognitive impairment; thus, we provided additional supporting evidence of validity for the new Health LiTT. Participants classified as having screened positive for cognitive impairment had Health LiTT scores that were 3.3 points lower than those with normal cognitive function after adjusting for other variables in the multivariable analysis. Because health literacy T-scores have a standard deviation of 10 , this difference corresponds to an effect size of 0.33 , which is considered "moderate" in magnitude [33]. We have used an effect size of 0.33 or larger to define important differences on patient-reported outcome measures [34]. Indeed, because none of the patients approached and enrolled in the parent study demonstrated severe cognitive impairment that would have deemed them ineligible, we were mostly comparing mild cognitive impairment with no cognitive impairment in this unplanned secondary analysis, which would have a smaller effect size.

\subsection{Sensitivity analysis}

In the sensitivity analysis, more variance in health literacy was explained when cognitive impairment was measured by the two component scores rather than the overall dichotomous 
classification, which is not surprising as dichotomizing may lead to loss of information [35]. Health literacy was more strongly associated with the CDT than with the WRT component of the Mini-Cog screening tool. Baker et al. also found that a visuospatial task (copying overlapping pentagons) was more strongly associated with health literacy as measured by the Short-Test of Functional Health Literacy in Adults (S-TOFHLA) than any other cognitive task assessed, including a delayed word recall task [7]. The S-TOFHLA measures reading comprehension and uses visual prompts such as an appointment card and a prescription label to measure numeracy. Others have found that processing speed, as measured by the Letter Comparison and Pattern Comparison tasks, was more strongly associated with S-TOFHLA reading comprehension scores than other tasks including working memory $[8,12]$; however, these studies did not include the numeracy part of the TOFHLA nor did they measure visuospatial skills specifically.

One possible explanation for the stronger association between health literacy and visuospatial skills in our study may be related to Health LiTT item format. All document and most quantitative items in the Health LiTT have health-related prompts (e.g., charts, tables, graphs) displayed on the touchscreen. Answering these items requires finding and interpreting information embedded in the prompt. Although the prose items do not include health-related prompts, navigating the display of the text and responses may also require visuospatial skills. Others have noted that responding to health literacy items engages several cognitive abilities [13,36], but one interpretation of our results is that answering Health LiTT questions may engage certain cognitive abilities more than others. A second explanation for the stronger association between health literacy and CDT may be related to the difficulty of the task. Roughly $67 \%$ of participants correctly recalled all three words in the WRT, whereas only $41 \%$ produced normal clock drawings, thus the CDT may be a more discriminating task when evaluated separately.

We observed lower health literacy among minorities, as has been reported elsewhere [ $8-10$, 37]. Gender was not a significant correlate of health literacy in our study. Mixed results have been reported for gender; either there is no association with health literacy $[10,11,38]$ or women have higher health literacy than men [8, 9,37]. Better physical function [10] and better mental health $[9,10]$ as measured by the SF-36 have been shown to be positively associated with higher health literacy, although only physical health was a significant correlate in our study. Due to the cross-sectional nature of our study, it is not possible to determine whether a history of poor health literacy contributes to worse health [39] or whether poor health leads to worse health literacy [8]. Household income has rarely been included in multivariable analyses of the correlates of health literacy; therefore, it is difficult to interpret whether the lack of significance in our study is typical.

Based on the results in Tables 3 and 4, there is no relationship between age and health literacy in our data (unadjusted beta for age $=-0.006, \mathrm{p}=0.87$; adjusted beta $=0.03, \mathrm{p}=$ 0.44 ). Some previous studies have reported a significant inverse relationship between age and health literacy $[9,10,37,40]$, even for patient samples similar to ours (i.e., predominantly minority, low SES, age range 18-88) [38]. These studies differ from ours in that the sample sizes were very large and participants were over 65 years of age $[9,10,37]$. The Gazmararian et al. [37], Baker et al. [9], and Wolf et al. [10] reports cited here are all based on the same "Prudential Health Literacy Study" and therefore should be counted as one study rather than three separate studies showing an association between health literacy and age. Furthermore, as acknowledged by Baker et al., the reading comprehension portion of the TOFHLA is timed. As a result, the relationship between age and health literacy may be due in part from older participants being unable to complete the test in the allotted time [9]. Health LiTT is not timed - patients can take as long as they want, and the average time to complete the 30 -item assessments used in the calibration study was approximately 18 
minutes (median time, 15 minutes) [2]. In a study of HIV patients (age range 22-69, average 40.2 years), Kalichman and Rompa did not find an association between health literacy and age [11]. Morrow et al. observed that age was inversely associated with health literacy in a sample of 314 community dwelling adults (age range 47-89, average 62.9 years), but this association did not hold after adjusting for other variables [8]. Finally, Federman et al. did not observe a significant association between age and health literacy category (inadequate, marginal, adequate) in a sample of community-dwelling older adults (45\% age 75+) [6]. In summary, currently there is insufficient evidence that age is a consistent independent correlate of health literacy across the age spectrum.

Patients at the urban recruitment sites had higher health literacy than patients at suburban sites, and this effect remained statistically significant in the multivariable regression after adjusting for sociodemographic variables known to differ across sites. We anticipated that this covariate would be non-significant or only weakly significant. We investigated possible explanations for the strong site effect and conclude that different recruitment strategies at the urban and suburban sites may have contributed to this effect. Specifically, patients in the urban sites were primarily recruited in person by the research assistant while in a clinic waiting room, whereas most patients at the suburban clinics responded to a flyer posted at the clinics and contacted the research assistant assigned to those clinics with a request to participate. This difference in recruitment strategy may have resulted in patient samples that differed by some other factor not measured in our study (e.g., incentive to participate) that may be related to health literacy. Further investigation is needed to understand whether recruitment bias is responsible for the strong association between recruitment site and health literacy in this study.

\subsection{Limitations}

We assessed cognitive impairment in a fairly young clinical sample (mean age, 46) using the Mini-Cog, a brief screening tool for dementia that has been validated among older adults. A more comprehensive battery of cognitive function tests, including tests validated for younger subjects, could more definitively demonstrate the association between cognitive impairment and health literacy as measured by Health LiTT. Additional research is also needed to determine whether other samples of vulnerable populations have a high prevalence of positive screens for cognitive impairment and whether the etiology is environmental or neurological. Patients were recruited using a combination of convenience sampling and flyers; therefore, the sample may not be representative of the patient populations at these clinics. Furthermore, patients were recruited differentially at the urban and suburban sites, which may have introduced recruitment bias. These limitations in our recruitment efforts should mostly affect external validity of this study, but not the internal associations among the measures. Finally, our study design was cross-sectional; therefore, although we noted several statistically significant associations, we cannot discern the causal direction of the relationships between health literacy and the other variables evaluated.

\subsection{Conclusion}

Our results demonstrate that health literacy scores from Health LiTT behave as hypothesized, thereby providing additional evidence of validity for this new tool. We found the CDT was more strongly associated with health literacy than the WRT and that combining CDT and WRT scores from the Mini-Cog to derive an overall classification may mask some of the association between cognitive ability and health literacy. Possible explanations may be related to the type and difficulty of cognitive tasks engaged when completing a health literacy assessment. 


\subsection{Practice implications}

Health LiTT is a promising new instrument that can facilitate measurement of health literacy in research and clinical settings. This study illustrates that while scores for brief assessments of health literacy and cognitive function are related in a predictable direction, the nature of that relationship is complex. The efficacy of interventions designed to help patients overcome difficulty understanding health information may depend on whether poor health literacy (or poor cognitive function that is environmental in nature) versus true neurologically-based cognitive impairment is responsible for the difficulty. Additional research to better understand why patients perform poorly on these assessments may inform interventions tailored to address the underlying basis for difficulty understanding health information.

\section{Acknowledgments}

\section{Role of funding}

This study was supported in part by grant number R01-HL081485 from the National Heart, Lung, and Blood Institute.

The authors thank Katy Wortman for data management; Patricia O'Neil and Lindsay Norgaard for scoring the Mini-Cog clock drawings; Seung Choi, Jeremiah Aakre, Shane Pankratz and Paul Novotny for statistical analysis support; and David Eton for reviewing an earlier version of this manuscript. Finally, we thank all of the patients who participated in this study.

\section{References}

1. Hahn E, Choi S, Griffith J, Yost K, Baker D. Health Literacy Assessment Using Talking Touchscreen Technology (Health LiTT): a new Item response theory-based measure of health literacy. J Health Commun. 2011; 16:150-162. [PubMed: 21951249]

2. Yost KJ, Webster K, Baker DW, Jacobs EA, Anderson A, Hahn EA. Acceptability of the talking touchscreen for health literacy assessment. J Health Commun. 2010; 15(Suppl 2):80-92. [PubMed: 20845195]

3. Yost KJ, Webster K, Baker DW, Choi SW, Bode RK, Hahn EA. Bilingual health literacy assessment using the Talking Touchscreen/la Pantalla Parlanchina: development and pilot testing. Patient Educ Couns. 2009; 75:295-301. [PubMed: 19386462]

4. Yost, K.; Choi, S.; Waite, K.; Lakhan, M.; Wolf, M.; EA, H. Health Literacy Annual Research Conference. Chicago, IL: Boston University Medical Campus; 2011. "Health Literacy Assessment Using Talking Touchscreen Technology" (Health LiTT) is a valid measure of health literacy.

5. Crocker, L.; Algina, J. Introduction to Classical \& Modern Test Theory. Orlando, FL: Harcourt Brace Jovanovich College Publishers; 1986.

6. Federman AD, Sano M, Wolf MS, Siu AL, Halm EA. Health literacy and cognitive performance in older adults. J Am Geriatr Soc. 2009; 57:1475-1480. [PubMed: 19515101]

7. Baker DW, Gazmararian JA, Sudano J, Patterson M, Parker RM, Williams MV. Health literacy and performance on the Mini-Mental State Examination. Aging Ment Health. 2002; 6:22-29. [PubMed: 11827619]

8. Morrow D, Clark D, Tu W, Wu J, Weiner M, Steinley D, Murray MD. Correlates of health literacy in patients with chronic heart failure. Gerontologist. 2006; 46:669-676. [PubMed: 17050758]

9. Baker DW, Gazmararian JA, Sudano J, Patterson M. The association between age and health literacy among elderly persons. J Gerontol B Psychol Sci Soc Sci. 2000; 55:S368-S374. [PubMed: 11078114]

10. Wolf MS, Feinglass J, Thompson J, Baker DW. In search of 'low health literacy': threshold vs gradient effect of literacy on health status and mortality. Soc Sci Med. 2010; 70:1335-1341. [PubMed: 20167411] 
11. Kalichman SC, Rompa D. Functional health literacy is associated with health status and healthrelated knowledge in people living with HIV-AIDS. J Acquir Immune Defic Syndr. 2000; 25:337344. [PubMed: 11114834]

12. Levinthal BR, Morrow DG, Tu W, Wu J, Murray MD. Cognition and health literacy in patients with hypertension. J Gen Intern Med. 2008; 23:1172-1176. [PubMed: 18459011]

13. Wolf MS, Curtis LM, Wilson EA, Revelle W, Waite KR, Smith SG, Weintraub S, Borosh B, Rapp DN, Park DC, Deary IC, Baker DW. Literacy, cognitive function, and health: results of the LitCog Study. J Gen Intern Med. 2012; 27:1300-1307. [PubMed: 22566171]

14. Hahn EA, Choi SW, Griffith JW, Yost KJ, Baker DW. Health literacy assessment using talking touchscreen technology (Health LiTT): a new item response theory-based measure of health literacy. J Health Commun. 2011; 16(Suppl 3):150-162. [PubMed: 21951249]

15. Borson S, Scanlan JM, Chen P, Ganguli M. The Mini-Cog as a screen for dementia: validation in a population-based sample. J Am Geriatr Soc. 2003; 51:1451-1454. [PubMed: 14511167]

16. Borson S, Scanlan J, Brush M, Vitaliano P, Dokmak A. The mini-cog: a cognitive 'vital signs' measure for dementia screening in multi-lingual elderly. Int J Geriatr Psychiatry. 2000; 15:10211027. [PubMed: 11113982]

17. Scanlan J, Borson S. The Mini-Cog: receiver operating characteristics with expert and naive raters. Int J Geriatr Psychiatry. 2001; 16:216-222. [PubMed: 11241728]

18. Borson S, Brush M, Gil E, Scanlan J, Vitaliano P, Chen J, Cashman J, Sta Maria MM, Barnhart R, Roques J. The Clock Drawing Test: utility for dementia detection in multiethnic elders. J Gerontol A Biol Sci Med Sci. 1999; 54:M534-M540. [PubMed: 10619314]

19. Morris JC, Heyman A, Mohs RC, Hughes JP, van Belle G, Fillenbaum G, Mellits ED, Clark C. The Consortium to Establish a Registry for Alzheimer's Disease (CERAD). Part I Clinical and neuropsychological assessment of Alzheimer's disease. Neurology. 1989; 39:1159-1165. [PubMed: 2771064]

20. Hahn EA, Cella D, Chassany O, Fairclough DL, Wong GY, Hays RD. Precision of health-related quality-of-life data compared with other clinical measures. Mayo Clin Proc. 2007; 82:1244-1254. [PubMed: 17908530]

21. Hays RD, Bjorner JB, Revicki DA, Spritzer KL, Cella D. Development of physical and mental health summary scores from the patient-reported outcomes measurement information system (PROMIS) global items. Qual Life Res. 2009; 18:873-880. [PubMed: 19543809]

22. Weiss B, Reed R, Kligman E. Literacy skills and communication methods of low-income older persons. Patient Educ Couns. 1995; 25:109-119. [PubMed: 7659623]

23. Barnes DE, Tager IB, Satariano WA, Yaffe K. The relationship between literacy and cognition in well-educated elders. J Gerontol A Biol Sci Med Sci. 2004; 59:390-395. [PubMed: 15071084]

24. Glymour MM, Manly JJ. Lifecourse social conditions and racial and ethnic patterns of cognitive aging. Neuropsychol Rev. 2008; 18:223-254. [PubMed: 18815889]

25. Shulman KI. Clock-drawing: is it the ideal cognitive screening test? Int J Geriatr Psychiatry. 2000; 15:548-561. [PubMed: 10861923]

26. Storey JE, Rowland JT, Basic D, Conforti DA. Accuracy of the clock drawing test for detecting dementia in a multicultural sample of elderly Australian patients. International Psychogeriatrics / IPA. 2002; 14:259-271. [PubMed: 12475087]

27. Storey JE, Rowland JT, Basic D, Conforti DA, Dickson HG. The Rowland Universal Dementia Assessment Scale (RUDAS): a multicultural cognitive assessment scale. International Psychogeriatrics / IPA. 2004; 16:13-31. [PubMed: 15190994]

28. Ramirez M, Teresi JA, Holmes D, Gurland B, Lantigua R. Differential item functioning (DIF), the Mini-Mental State Examination (MMSE) Overview, sample, and issues of translation. Med Care. 2006; 44:S95-S106. [PubMed: 17060840]

29. Fillenbaum G, Heyman A, Williams K, Prosnitz B, Burchett B. Sensitivity and specificity of standardized screens of cognitive impairment and dementia among elderly black and white community residents. J Clin Epidemiol. 1990; 43:651-660. [PubMed: 2370572]

30. Borson S, Scanlan JM, Watanabe J, Tu SP, Lessig M. Simplifying detection of cognitive impairment: comparison of the Mini-Cog and Mini-Mental State Examination in a multiethnic sample. J Am Geriatr Soc. 2005; 53:871-874. [PubMed: 15877567] 
31. Kamat SM, Kamat AS, Grossberg GT. Dementia risk prediction: are we there yet? Clin Geriatr Med. 2010; 26:113-123. [PubMed: 20176297]

32. Manly JJ, Jacobs DM, Touradji P, Small SA, Stern Y. Reading level attenuates differences in neuropsychological test performance between African American and White elders. J Int Neuropsychol Soc. 2002; 8:341-348. [PubMed: 11939693]

33. Cohen, J. Statistical Power Analysis for the Behavioral Sciences. Second ed.. Hillsdale, NJ: Lawrence Erlbaum Associates; 1988.

34. Yost KJ, Eton DT. Combining distribution- and anchor-based approaches to determine minimally important differences: The FACIT experience. Eval Health Prof. 2005; 28:172-191. [PubMed: 15851772]

35. Cohen J. The cost of dichotomization. Applied Psychological Measurement. 1983; 7:249-253.

36. Baker DW, Wolf MS, Feinglass J, Thompson JA. Health literacy, cognitive abilities, and mortality among elderly persons. J Gen Intern Med. 2008; 23:723-726. [PubMed: 18330654]

37. Gazmararian JA, Baker DW, Williams MV, Parker RM, Scott TL, Green DC, Fehrenbach SN, Ren J, Koplan JP. Health literacy among Medicare enrollees in a managed care organization. JAMA. 1999; 281:545-551. [PubMed: 10022111]

38. Williams MV, Parker RM, Baker DW, Parikh NS, Pitkin K, Coates WC, Nurss JR. Inadequate functional health literacy among patients at two public hospitals. JAMA. 1995; 274:1677-1682. [PubMed: 7474271]

39. DeWalt DA, Berkman ND, Sheridan S, Lohr KN, Pignone MP. Literacy and health outcomes: a systematic review of the literature. J Gen Intern Med. 2004; 19:1228-1239. [PubMed: 15610334]

40. Schillinger D, Barton LR, Karter AJ, Wang F, Adler N. Does literacy mediate the relationship between education and health outcomes? A study of a low-income population with diabetes. Public Health Rep. 2006; 121:245-254. [PubMed: 16640146] 


\section{Medications for Mr. Beta}

\begin{tabular}{|llll|}
\hline Medication & $\begin{array}{l}\text { Start } \\
\text { Date }\end{array}$ & $\begin{array}{l}\text { End } \\
\text { Date }\end{array}$ & Instructions \\
\hline Hanebrex: $200 \mathrm{mg}$ tablets & Aug. 27 & Sept. 26 & 1 Tablet daily \\
Yostatin: $250 \mathrm{mg}$ tablets & Mar. 8 & None & 1 Tablet twice daily \\
Nandozol: 90 mcg per puff & Mar. 8 & None & $\begin{array}{l}1-2 \text { Puffs by mouth } \\
\text { every 4-6 hours as needed }\end{array}$ \\
Cellacillin: $250 \mathrm{mg}$ tablets & Apr. 22 & Apr. 29 & $\begin{array}{c}\text { 2 Tablets on the first day, } \\
\text { then 1 Tablet daily after that }\end{array}$ \\
& & & \\
\hline
\end{tabular}

Look at the Medications for Mr. Beta. How many tablets of Cellacillin should he take on the third day?

1

2

Figure 1.

Example Health LiTT document item 

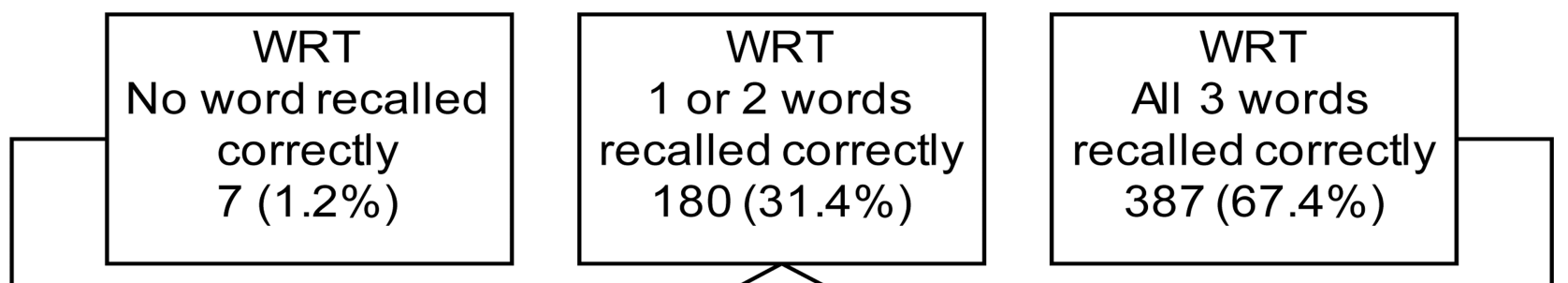

\begin{tabular}{|c|}
\hline Overall Mini-Cog \\
classification: \\
Screen positive for \\
cognitive impairment \\
$118(20.6 \%)$
\end{tabular}

111 Abnormal $($ score $=1-3)$
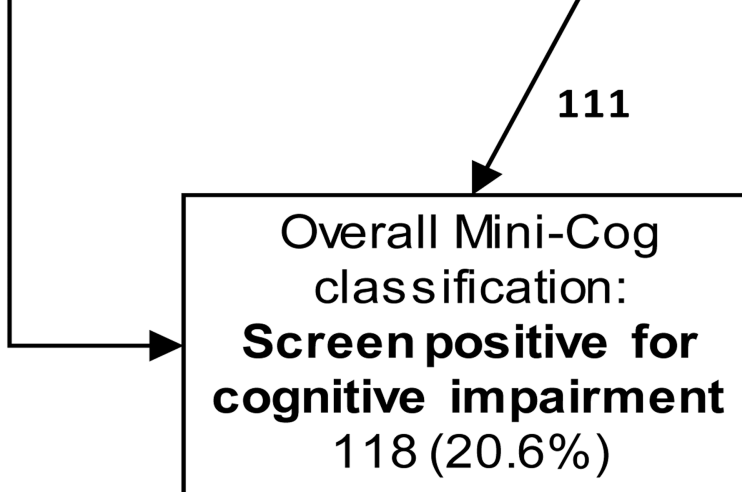

WRT: word recall task, CDT: clock drawing task

Clock drawings were independently scored by 2 raters. Weighted kappa=0.755.

Figure 2.

Mini-Cog scoring $(\mathrm{n}=574)$ 
Table 1

Characteristics of sample $(n=574)$.

\begin{tabular}{|c|c|}
\hline Characteristic & $\mathrm{n}(\%)$ \\
\hline Urban recruitment sites & $266(46.3)$ \\
\hline Female & $291(50.7)$ \\
\hline \multicolumn{2}{|l|}{ Race/ethnicity } \\
\hline African-American, non-Hispanic & $387(67.4)$ \\
\hline White, non-Hispanic & $93(16.2)$ \\
\hline Other, non-Hispanic & $23(4.0)$ \\
\hline Hispanic, any race & $71(12.4)$ \\
\hline \multicolumn{2}{|l|}{ Age } \\
\hline $21-39$ & $154(26.8)$ \\
\hline $40-49$ & $157(27.4)$ \\
\hline $50-59$ & $203(35.4)$ \\
\hline $60-77$ & $57(9.9)$ \\
\hline Missing & $3(0.5)$ \\
\hline No health insurance & $287(50.0)$ \\
\hline \multicolumn{2}{|l|}{ Household Income } \\
\hline$<\$ 10,000$ & $241(42.0)$ \\
\hline$\$ 10,000-\$ 24,999$ & $198(34.5)$ \\
\hline$\$ 25,000+$ & $87(15.2)$ \\
\hline Missing & $48(8.4)$ \\
\hline \multicolumn{2}{|l|}{ Highest grade completed } \\
\hline$<$ High School & $102(17.8)$ \\
\hline High school graduate/GED & $219(38.2)$ \\
\hline Some college & $178(31.0)$ \\
\hline College graduate or advanced degree & $75(13.1)$ \\
\hline \multicolumn{2}{|l|}{ Health status, mean (SD) } \\
\hline Global mental health & $44.5(8.9)$ \\
\hline Global physical health & $43.0(9.0)$ \\
\hline
\end{tabular}

Patient Educ Couns. Author manuscript; available in PMC 2014 November 01. 
Table 2

a Association between cognitive impairment and continuous study variables: t-tests.

\begin{tabular}{llll} 
Variable & Normal & $\begin{array}{l}\text { Screen } \\
\text { Positive, } \\
\text { Cognitive } \\
\text { Impairment }\end{array}$ & p-value \\
\hline & $\underline{\text { Mean (SD) }}$ & $\underline{\text { Mean (SD) }}$ & \\
Age & $45.5(12.0)$ & $48.4(10.5)$ & 0.02 \\
Global mental health & $44.9(8.9)$ & $43.0(8.7)$ & 0.04 \\
Global physical health & $43.4(9.0)$ & $41.7(8.9)$ & 0.08 \\
Health LiTT T-score & $50.8(10.1)$ & $46.4(9.0)$ & $<.001$ \\
\hline
\end{tabular}

b

Association between cognitive impairment and ordinal and nominal study variables: chi-square tests.

\begin{tabular}{|c|c|c|c|}
\hline Variable & $\begin{array}{l}\text { Normal } \\
\mathbf{n}^{*}(\%)\end{array}$ & $\begin{array}{l}\text { Screen } \\
\text { Positive, } \\
\text { Cognitive } \\
\text { Impairment } \\
n^{*}(\%)\end{array}$ & p-value \\
\hline \multicolumn{4}{|l|}{ Recruitment Site } \\
\hline Suburban & $235(76.3)$ & $73(23.7)$ & 0.04 \\
\hline Urban & $221(83.1)$ & $45(16.9)$ & \\
\hline \multicolumn{4}{|l|}{ Gender } \\
\hline Male & $222(78.4)$ & $61(21.6)$ & 0.56 \\
\hline Female & $234(80.4)$ & $57(19.6)$ & \\
\hline \multicolumn{4}{|l|}{ Race/ethnicity } \\
\hline African-American, non-Hispanic & $298(77.0)$ & $89(23.0)$ & \\
\hline White, non-Hispanic & $74(79.6)$ & $19(20.4)$ & 0.05 \\
\hline Other, non-Hispanic & $22(95.7)$ & $1(4.3)$ & \\
\hline Hispanic, any race & $62(87.3)$ & $9(12.7)$ & \\
\hline \multicolumn{4}{|l|}{ Household income from all sources } \\
\hline$<\$ 10,000$ & $181(75.1)$ & $60(24.9)$ & \\
\hline$\$ 10,000-\$ 24,999$ & $159(80.3)$ & $39(19.7)$ & 0.08 \\
\hline$\$ 25,000+$ & $75(86.2)$ & $12(13.8)$ & \\
\hline \multicolumn{4}{|l|}{ Highest grade completed } \\
\hline$<$ High School & $80(78.4)$ & $22(21.6)$ & \\
\hline High school graduate/GED & $177(80.8)$ & $42(19.2)$ & 0.83 \\
\hline Some college & $138(77.5)$ & $40(22.5)$ & \\
\hline College graduate or advanced degree & $61(81.3)$ & $14(18.7)$ & \\
\hline
\end{tabular}

Sample sizes for each variable may not sum to 574 due to missing data. 
Table 3

Simple linear regression of Health LiTT scores.

\begin{tabular}{|c|c|c|c|c|}
\hline Variable & $\mathbf{r}^{2}$ & b & SE & $\boldsymbol{F}$ \\
\hline Urban recruitment site & $2.1 \%$ & 2.88 & 0.83 & $12.0^{* * *}$ \\
\hline Age & $0.0 \%$ & -0.003 & 0.04 & 0.01 \\
\hline Female & $0.1 \%$ & 0.72 & 0.84 & 0.74 \\
\hline Race/ethnicity & $13.1 \%$ & & & $28.6^{* * * *}$ \\
\hline Black, Non-Hispanic & & -9.3 & 1.1 & \\
\hline Other, Non-Hispanic & & -3.9 & 2.2 & \\
\hline Hispanic, any race & & -3.9 & 1.5 & \\
\hline \multicolumn{5}{|c|}{ White, Non-Hispanic (reference category) } \\
\hline Household income from all sources & $1.9 \%$ & & & $5.6^{* * *}$ \\
\hline \multicolumn{5}{|l|}{$<\$ 10,000$ (reference category) } \\
\hline$\$ 10,000-\$ 24,999$ & & 0.95 & 0.92 & \\
\hline$\$ 25,000+$ & & 4.1 & 1.2 & \\
\hline \multicolumn{5}{|l|}{ Health Status } \\
\hline Global mental health & $0.58 \%$ & 0.22 & 0.12 & 3.2 \\
\hline Global physical health & $2.1 \%$ & 0.44 & 0.13 & $12.0^{* * * *}$ \\
\hline Education & $11.9 \%$ & & & $25.6^{* * * *}$ \\
\hline \multicolumn{5}{|l|}{$<$ High school (reference category) } \\
\hline High school & & 0.48 & 1.1 & \\
\hline Some college & & 4.1 & 1.2 & \\
\hline College grad or higher & & 10.6 & 1.4 & \\
\hline Overall cognitive impairment & $3.2 \%$ & -4.4 & 1.0 & $18.9^{* * * *}$ \\
\hline Clock drawing task (CDT) score & $5.7 \%$ & -3.0 & 0.52 & $34.3^{* * * *}$ \\
\hline Word recall task (WRT) score & $2.3 \%$ & 2.3 & 0.63 & $13.4^{* * *}$ \\
\hline
\end{tabular}

$r^{2}$ : coefficient of simple correlation, interpreted as the amount of variance in health literacy scores explained by the simple regression model. b: unstandardized regression coefficient

SE: standard error

F: F-test statistic for testing whether there is a regression relation between Health LiTT scores and the independent variable.

*

$\mathrm{p}<0.05$,

* $\mathrm{p}<0.01$

****

$\mathrm{p}<0.001$ 
Table 4

Unstandardized regression coefficients from the stepwise multivariable regression analyses ${ }^{a}$.

\begin{tabular}{|c|c|c|c|c|}
\hline Variable & Step 1 & Step 2 & Step 3 & Step $3^{b}$ \\
\hline Urban recruitment sites & $2.0^{*}$ & $2.8^{* * *}$ & $2.6^{* *}$ & $2.2^{* *}$ \\
\hline Age & 0.05 & 0.04 & 0.05 & 0.07 \\
\hline Female & 1.2 & 0.60 & 0.57 & 0.63 \\
\hline \multicolumn{5}{|l|}{ Race/ethnicity } \\
\hline Black, Non-Hispanic & $-8.6^{* * *}$ & $-7.4^{* * *}$ & $-7.4^{* * *}$ & $-6.9^{* * * *}$ \\
\hline Other, Non-Hispanic & -3.9 & -3.9 & $-4.3^{*}$ & -3.6 \\
\hline Hispanic, any race & $-4.0^{* * *}$ & $-3.0 *$ & $-3.1^{*}$ & $-2.9^{*}$ \\
\hline \multicolumn{5}{|c|}{ White, Non-Hispanic (reference category) } \\
\hline \multicolumn{5}{|l|}{ Household income from all sources } \\
\hline \multicolumn{5}{|l|}{$<\$ 10,000$ (reference category) } \\
\hline$\$ 10,000-\$ 24,999$ & -0.36 & -0.29 & -0.36 & -0.34 \\
\hline$\$ 25,000+$ & $2.5^{*}$ & 1.2 & 0.98 & 1.2 \\
\hline \multicolumn{5}{|l|}{ Health Status } \\
\hline Global mental health & -0.004 & -0.02 & -0.03 & -0.03 \\
\hline Global physical health & $0.17^{* *}$ & $0.14^{*}$ & $0.15^{* *}$ & $0.15^{* *}$ \\
\hline \multicolumn{5}{|l|}{ Education } \\
\hline \multicolumn{5}{|l|}{$<$ High school (reference category) } \\
\hline High school & -- & 0.67 & 0.55 & 0.39 \\
\hline Some college & -- & $4.4^{* * *}$ & $4.3^{* * *}$ & $3.9^{* *}$ \\
\hline College grad or higher & -- & $9.9^{* * *}$ & $9.8^{* * *}$ & $9.7^{* * *}$ \\
\hline Overall cognitive impairment & -- & -- & $-3.3^{* * *}$ & -- \\
\hline Clock drawing task (CDT) score & -- & -- & -- & $-2.4^{* * *}$ \\
\hline Word recall task (WRT) score & -- & -- & -- & 1.1 \\
\hline Model Adjusted $\mathbf{R}^{2}$ & $14.8 \%$ & $24.0 \%$ & $25.6 \%$ & $27.7 \%$ \\
\hline
\end{tabular}

${ }^{a}$ Adjusted for all other variables in the model

${ }^{b}$ Sensitivity analysis. Overall cognitive impairment replaced with both the CDT and WRT scores.

-- Variable not included in the model

p $<0.05$,

* $\mathrm{p}<0.01$,

**** $\mathrm{p}<0.001$

$\mathrm{R}^{2}$ : coefficient of multiple determination, interpreted as the amount of variance in heath literacy scores explained by the multivariable regression model. 